\title{
FURTHER RADIO OBSERVATIONS OF THE FIRST SATELLITE
}

$\mathrm{T}$ HE radio signals from the first Russian Larth satellite were recorded at the University of Illinois Observatory during the period October 5-24 on 40 Mc./s. and on $20 \mathrm{Mc} / \mathrm{s}$. This communication dials with the observations on $40 \mathrm{Mc} / \mathrm{s}$. made with twoelement interferometers, one with a north south base-line of 5.45 wave-lengths, the other with a north-south base-line of 1 wave-length. The first instrument, was constructed during the night of October 4-5, the second on October 11. The latter was fed out of phase for lobe-ambiguity resolution. The rusults were recorded on Esterline-Angus graphic recordors running at $1 \mathrm{ft} . / \mathrm{min}$.

The interpretation of the records was complicated by the fact that all the eleven lobes of the pattern of the main north south interferometer never appeared on the record of any one passage of the satellite. However, it proved possible to overcome this difficulty, particularly after October 11 , when the second instrument came into use. The instruments were located on the parallel N. $40^{\circ} 1 \cdot 1^{\prime}$. The times at which the first artificial Farth satellite crossed this parallel, together with estimates of the altitude above the horizon at the moment of closest approach, were communicated as rapidly as possible to the Smithsonian Astrophysical Observatory, Cambridge, Mass., and the Naval Research Laboratory, Washington. The mean absolute error in the times of erossing was $3 \mathrm{~s}$.

Since the radio-signals ceased, the computations have been refined. The period of the satellite and the regression of the nodes of its orbit can be deduced from our observations. The best representation of the period $(P)$ during the interval October $5-24$ is : $P=96 \mathrm{~m} .09 \cdot 8 \mathrm{~s} .-0 \cdot 1293 \mathrm{~s} . n-7 \cdot 797 \mathrm{~s} . \times 10^{-5} n^{2}$

where $n$ is the number of revolutions since our adopted zero, which was the southbound crossing of our parallel on October 5d. 13h. $30 \mathrm{~m}$. 01s. U.T. The regression of the nodes can be expressed as follows : the local mean solar time at the point of southbound crossing of our parallel is :

(8h. $11 \mathrm{~m} . \pm 2 \mathrm{~m}).-(1 \cdot 100 \mathrm{~m} . \pm 0 \cdot 006 \mathrm{~m})$.

The probable errors shown are calculated from internal consistency. The observations were made under the direction of George W. Swenson, jun., and the interpretation of the re ults was carried out by Ivan R. King with the assistance of Stanley P. Wyatt, jun.

These formulxe are based on the records obtained at our station alone. On October 26 a radio broadcast. from Moscow mentioned that the period was $95.31 \mathrm{~lm}$. During that day, $n$ would increase from 313 to 318 between $9 \mathrm{~h}$. and 18h. U.T. Thus formula (1) would give periods ranging from $95 \cdot 36 \mathrm{~m}$. to $95 \cdot 35 \mathrm{~m}$. On October 28, the Smithsonian Astrophysical Observatory released a statement that, on October $25 \mathrm{~d}$. $2 \mathrm{~h}$. $25 \mathrm{~m}$. U.T., the period was $95 \cdot 44 \mathrm{~m}$., and the daily variation of the period was $-2 \cdot 4 \mathrm{~s}$. It is not known whether our results entered into tho computation of those of the Smithsonian. October 25d. $2 \mathrm{~h}$. $25 \mathrm{~m}$. corresponds to $n=294$ and this gives $P=$ $95 \cdot 42 \mathrm{~m}$., with a daily variation of $-2 \cdot 6 \mathrm{~s}$.

Records on $20 \mathrm{Mc}$./s. were also obtained under the direction of Edgar C. Hayden and these, togethor with the 4u Mc./s. results, are expected to furnish con- siderable information about the ionosphere. These records have not yet been analysed.

IVAN R. KING

G. C. MeVintie

George W. Swenson, Jun.

STANLEY P. WyatT, JUN.

University of Illinois Observatory, Urbana, Illinois.

Nov. 1.

THE $40 \mathrm{Mc} / \mathrm{s}$. frequency of the first Russian Earth satellite has beon measured at Chelmsford for the condition of zero Dopplor effect.

The method adopted presupposed that the signal might be modulated at the source or during propagation in such a way as to make fully automatic measure. ments difficult, so the fine component of local comparison frequency was obtained from an audio oscillator steered manually to follow the Joppler variations. For a high percentage of the time the 'steering' error was held less than $2 \mathrm{c.} / \mathrm{s}$. by using a circular time-base on a cathode ray oscilloseope. The audio oscillator output was connected to a frequency recorder having scales of 4.5 in. per $1,000 \mathrm{c.} / \mathrm{s}$. and 1 in. par 30 sec.

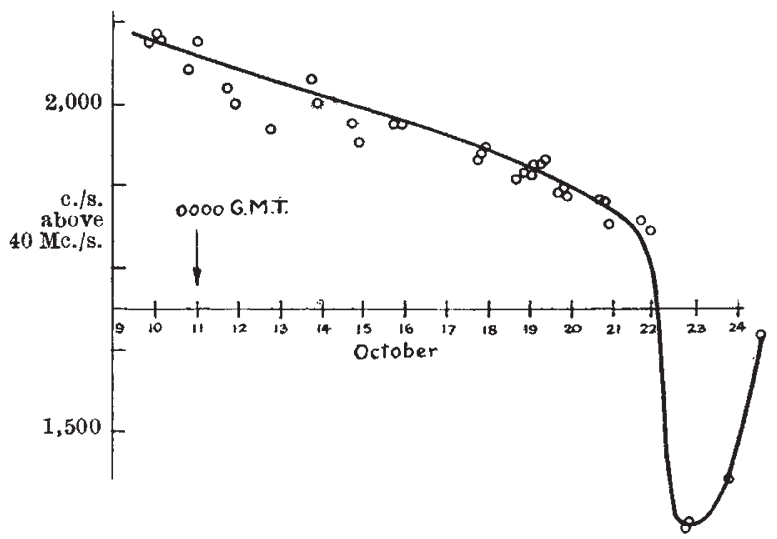

Fig. 1

The S-shaped Doppler curvos obtained were remarkably clean and symmetrical, so that the frequencies and times corresponding to nearest approach (zero Doppler effect) could be read off with useful accuracy. Fig. I shows the frequencies of zero Doppler effect deduced in respoct of 37 orbits observed between October 9 and 24, 1957. Signals were not heard after 1843 G.M.T. October 24.

The maximum rates of change of frequexcy observed for the various orbits covered the range of $33-4.5 \mathrm{c} / \mathrm{s} . / \mathrm{s}$., corresponding to approximate slantrange values of $224-1,500 \mathrm{~km}$. respectively.

The datum of the local $40 \mathrm{Mc} / \mathrm{s}$. comparison frequency was known to within 1 part in $10^{\circ}$.

Research Division,

NORMan LEa

Marconi's Wireless Telegraph Co., Ltd., Great Baddow,

Chelmsford, Essex. Oct. 30 . 